УДК 334.012(09)

ББК 65.290-03

\title{
ТРАДИЦИОННОЕ ХОЗЯЙСТВО В НАУЧНО-ИСТОРИЧЕСКОМ ДИСКУРСЕ
}

\begin{abstract}
Рассматривается эволюция понятия «традиционное хозяйство», использующегося в научных трудах. Делается вывод о необходимости определения содержания данного понятия. Предлагается вариант такого определения, основанный на признании традиционного хозяйства моделью экономической системы, используемой для исторических исследований.
\end{abstract}

Ключевые слова: традиционное хозяйство, теория модернизации, системный подход.

\section{A.M. KURYSHOV}

\section{TRADITIONAL ECONOMY IN SCIENTIFIC AND HISTORICAL DISCOURSE}

The evolution of the concept of "traditional economy" used in scientific works is considered. The conclusion is made about the need to determine the content of this concept. A variant of such a definition is proposed, based on the recognition of the traditional economy as a model of the economic system used for historical research.

Keywords: traditional economy, modernization theory, structuralsystem method.

Проблема научного определения «традиционного хозяйства» на современном этапе развития научного знания остается нерешенной, несмотря на частное употребление этого термина в трудах исследователей различного профриля - географов, этнографов, историков, экономистов. Между тем потребность в придании «традиционному хозяйству» более или менее фриксированного смысла, безусловно, есть: во-первых, потому что растет число междисциплинарных научных исследований, так или иначе затрагивающих "традиционное хозяйство», но понимающих его по-разному, что в известном смысле препятствует перспективам развития данной научной тематики; во-вторых, потому что термин «традиционное хозяйство» все чаще фригурирует в риторике сторонников «национального возрождения» (безотносительно к тому, о каком этносе идет речь) как один из символов и, одновременно, важных средств такого «возрождения», что придает некий идеологический смысл термину.

В основе понятия «традиционное хозяйство», часто используемого исследователями, лежит другое - «традиционное общество». Это по- 
нятие было сформулировано еще в первые десятилетия после Второй мировой войны, 一 как характеристика такого типа социально-экономической сферы жизни общества, который противопоставляется (и предшествует) модерну, современности. Вот как характеризует традиционное общество апологет теории модернизации У. Ростоу: «Традиционным мы называем общество, структура которого определяется его ограниченными производственными функциями, опирающимися на до-ньютоновскую науку и технологию и до-ньютоновские представления о внешнем мире...» [4, с. 15], и далее: «важнейшим признаком традиционного общества является то, что в нем неизбежен некоторый предел роста выработки продукции на душу населения» [4, с. 16], «традиционные общества направляли очень большую часть своих ресурсов на сельскохозяйственное производство. Это объясняется низкой производительностью традиционных обществ. Система сельского хозяйства определяла иерархию социальной структуры с ее очень ограниченной возможностью вертикальных перемещений из одного слоя общества в другой» $[4$, с. 16].

Противопоставление «традиции» и современности, как мы видим, касается технологического уровня и целеполагания хозяйственной деятельности: в традиционном обществе 1) существуют пределы экономического роста, и 2) хозяйственная деятельность направлена на постоянное воспроизводство существующих социальных отношений. С точки зрения технологии традиционное хозяйство может быть описано как относительно примитивное, в структуре производства продукта преобладает сельское хозяйство, а по сути оно - стадия экономического развития, которая неизбежно сменяется следующей стадией. Теоретическими основами таких представлений стали эволюционизм (в части тезиса об однолинейном прогрессивном развитии общества, которое вызывается эндогенными фракторами) и фрункционализм (в части тезиса о несовместимости традиции и современности).

Важно и идеологическое значение, вкладываемое сторонниками модернизационных концепций 1950-1960-х гг. в понятия «традиционное общество» и "традиционное хозяйство», - они противопоставляются европейскому варианту развития, ибо сама модернизация понимается как вестернизация, распространение на весь мир опыта социальноэкономического развития Запада. Она есть совокупность процессов, утверждающих рыночные отношения, сопровождается технологическими прорывами и приводит, в конечном итоге, к формированию общества массового потребления. В силу такой «социальной» направленности модернизационных процессов они представляются как предпочтительные, прогрессивные, желаемые, в то время как традиционное общество олицетворяет собой все косное, устаревшее, требующее замены. Такое, хотя и не высказываемое явно, но подразумеваемое понимание «традиционного хозяйства» в трудах У. Ростоу, Д. Лернера, М. Леви стало 
«отражением социальных, экономических и политических успехов западного общества» [2, с. 70].

Обращение к модернизационным концепциям для построения теоретической основы обществоведческих (в том числе - исторических) исследований понятно, - это дает возможность представить исторический процесс цельно, строго и логично, позволяет сформулировать некие выводы, претендующие на роль закономерностей, придает научность исследованиям. Но объективно мы наблюдаем в разных временах и регионах различные темпы и формы трансформации общественных отношений. Это относится и к «традиционной экономике». Даже сторонники теории модернизации, наблюдая успешные варианты развития СССР, некоторых азиатских стран, отказались от однозначного понимания модернизации как осуществления перехода от традиционного общества к современному по западному образцу. Сначала (в 1970-е гг.) критике подвергся тезис об однолинейном прогрессивном развитии общества, инициированном внутренними причинами (Б. Мур, Д. Эптер, Д. Рюшемейер, А.Г. Франк, И. Валлерстайн), были разработаны модели частичной модернизации, модернизации, вызванной экзогенными факторами, периферийной модернизации и т.п., т.е. было признано, что модернизация может развиваться разными путями. Идеологическое значение теории модернизации теперь проявлялось в том, что она в целом противопоставлялась марксизму, выступала альтернативным ему объяснением исторического процесса. Затем, в 1980-е гг., пересмотру подверглось второе основание «классической школы модернизации» - тезис о несовместимости традиции и современности (С. Хантингтон, В. Дэвис, 3. Бауман). В работах этого периода заметно расширение исторической базы исследований и отход от чрезмерного схематизма предыдущих десятилетий. Такой подход позволил показать, что традиция (в том числе - традиционное хозяйство) всегда влияет на процессы модернизации, являясь одним из важнейших ее структурных элементов. После распада СССР и начала «взлета» Китая сторонники модернизационной теории снова подвергли ее пересмотру на основе «неомодернизационного анализа»: к признанию многовариантности модернизации и участию в ней традиций добавились тезисы о положительной (для социальной эволюции) роли некоторых традиций, о возможности прерывности социальной эволюции, о возможности отрицательных последствий модернизации, о значительной роли в процессе социальной эволюции отдельных коллективов и индивидов [2, с. 93-94].

Таким образом, модернизационная теория за десятилетия развития прошла путь от понимания модернизации (перехода от традиционного общества к современному) как процесса одновариантного и поступательного к признанию ее процессом многовариантным и сложным. Это подразумевает и изменение отношения к традиционному хозяйству как главной составной части «традиционного общества», - оно не должно 
восприниматься как признак отсталости. Тем не менее традиционное хозяйство в трудах исследователей продолжает ассоциироваться с теми характеристиками, которыми его наделяли еще представители «классической школы модернизации».

Именно к ним восходит определение традиционного хозяйства, ставшее классическим в экономической науке: «Хозяйственные системы многих слаборазвитых стран можно назвать традиционной, или патриархальной, экономикой, в которых методы производства, обмена товарами и распределения дохода определяются обычаями. Наследственность и кастовая принадлежность диктуют людям их экономические роли, и в силу этого господствует социально-экономический застой... Религиозные и культурные ценности здесь первичны по сравнению с экономической деятельностью, а общество отстаивает сохранение status quo» [1, с. 39]. Традиционная экономика экономистами прямо противопоставляется «инновационному типу экономики, характерному для западного мира», а характерными признаками ее называются «погруженность экономической деятельности в сети социальных связей, обязательств; неразрывная взаимосвязь между экономической и политической властью; отсутствие или слабо развитая специализации труда; вторичность по отношению к иным сферам социальной жизни (семья, религия, военная или государственная служба), а некоторые виды экономической деятельности (торговля, ростовщичество) являются по закону или в соответствии с нормами господствующей этики неодобряемыми; устойчивое сохранение традиционных способов осуществления производственной и экономической деятельности, низкий уровень внедрения технологических инноваций» [5, с. 105]. Если «скрестить» и предельно упростить определения традиционного хозяйства, даваемые экономической теорией и социологией, то получается то, что нам предлагают на просторах Интернета, определяя традиционную экономику такими чертами, как низкий уровень технологического развития, слабые экономические связи «между поселениями», неразвитая торговля, социальный и экономический застой, преобладание аграрного сектора [6].

При всей тенденциозности «экономико-теоретического» определения относительно «отсталости» традиционного хозяйства, оно имеет ряд преимуществ перед «социологическим» определением классиков теории модернизации. Во-первых, традиционное хозяйство определяется как система. Нередко, чаще - в этнографических работах, традиционное хозяйство предстает как простая совокупность традиций ведения хозяйства, т.е. по сути набор приемов и методов создания материальных благ. Такой подход не позволяет в процессе познания пойти дальше описания фактов. Для анализа же требуется нечто большее, и использование здесь структурно-системного метода представляется совершенно оправданным, поскольку традиционная экономика имеет все атрибуты 
системы: цель (воспроизводство социума), ресурсы, связь с внешней средой (природой, другими социумами), обратную связь, наконец, элементы (т.е. непосредственно хозяйственные традиции). Во-вторых, хотя традиционное хозяйство и противопоставляется «инновационной экономике», оно не определяется однозначно как стадия развития, скорее - как форма. Традиционное хозяйство может сосуществовать с «инновационной экономикой» во времени и пространстве. В-третьих, определяются более или менее четкие признаки, характеризующие систему традиционного хозяйства. Как и у У. Ростоу, признается ограниченность перспектив роста экономики в условиях традиционного общества (что обусловлено ограниченностью ресурсов и необходимостью делать выбор), но оставляется возможность по-разному интерпретировать процессы трансформации традиционного хозяйства: «Разные общества с различным культурным и историческим прошлым, разными обычаями и традициями, противоположными идеологическими устоями (не говоря уже о ресурсах, различающихся между собой и количественно, и качественно) используют разные институциональные структуры для решения реальной проблемы относительной нехватки ресурсов. Наиболее подходящий и продуктивный для такой экономической системы способ действий может оказаться непригодным для другой системы» [1, с. 39].

Преимущества данного определения традиционно хозяйства, к сожалению, нивелируются двумя важнейшими обстоятельствами. Первое: экономическая деятельность человека вряд ли может определяться исключительно выбором в условиях основного противоречия экономики. Как показал Карл Поланьи, термин «экономический» имеет формальное и содержательное значения. Формальное и используется чаще всего экономистами, оно основывается на определении экономики как выборе в условиях ограниченности ресурсов и безграничности потребностей, но это - теория. На практике реализуется содержательное значение, связанное с пониманием факта зависимости человека от природы и общества, оно «характеризует его взаимоотношения с природным и социальным окружением, которые обеспечивают ему средства удовлетворения материальных потребностей» [3, с. 62]. На протяжении большей части человеческой истории реального экономического выбора, который человек мог бы осознанно сделать, не было, человек лишь приспосабливался к условиям, его окружающим. Возможность выбора (достаточно ограниченная) появляется лишь тогда, когда экономические отношения перестают зависеть напрямую от других сфер общественной жизни, т.е. в условиях свободной рыночной экономики, век которой был очень короток, а распространение - крайне ограничено. «Формальное значение "экономического” представляет хозяйство как последовательность актов экономии ресурсов [acts of economizing] - иными словами, как совокупность выборов, вызванных дефицитом средств», в то время как реальное хозяйство — это 
«институционально оформленный процесс взаимодействия между человеком и окружающей средой, ведущий к постоянному обеспечению материальных средств для удовлетворения потребностей» [3, с. 66]. Таким образом, категории экономической теории, в том числе - приведенное выше определение «традиционной экономики», не могут применяться в научном анализе традиционного хозяйства, которое лежит за пределами свободного рынка. Здесь должны исследоваться нормы («институции») процесса природопользования в целях удовлетворения потребностей (что и есть «экономика»), а также закрепление этих норм («институты»).

Второе: система традиционного хозяйства, как и любая «система», определяемая исследователями общества, - это модель, ими сконструированная, но никак не прямое отражение реальной действительности, гораздо более разнообразной, сложной и непредсказуемой, нежели любая «система». Тем паче, что при конструировании «системы» исследователи опираются на анализ не собственно исторических фактов (событий, явлений, процессов), а научно-исторических фактов, т.е. умозаключений, полученных в ходе изучения собственно-исторических фактов. Поэтому «система традиционного хозяйства» может и должна использоваться наукой, но не как часть реальности, а как метод, позволяющий исследовать эту реальность. Системный подход позволяет получить более цельные и полные представления, но нельзя забывать, что это - лишь представления.

В свете сказанного выше мы предлагаем исходить при определении «традиционного хозяйства» из следующих положений: 1) традиционное хозяйство есть система; 2) система традиционного хозяйства есть не объект, а сама по себе предмет исследования, поскольку представляет собой модель общественных отношений, а не сами общественные отношения; 3) система традиционного хозяйства есть форма, а не этап развития экономики; 4) как система традиционное хозяйство обладает рядом признаков, характеризующих связи между его элементами - хозяйственными традициями.

Важнейшей проблемой, связанной с определением понятия традиционного хозяйства, является очерчивание признаков, характеризующих его как систему. Исходя из того, что традиционное хозяйство является системой, а не совокупностью хозяйственных традиций, и формой, а не стадией развития экономики, нам придется определить те признаки, которые, с одной стороны, отличают его от экономики рыночной и плановой (эти две формы современной экономики исследователями многократно противопоставлены и идентифицированы), с другой стороны - являются тем, что и делает традиционное хозяйство системой, определяет ее структуру, т.е. связи между элементами системы.

Первый и главный признак - прямая и непосредственная обусловленность хозяйственных традиций окружающими природными условиями, при этом социум не приспосабливает природу под себя, а, скорее, 
приспосабливается к ней. Такой подход к хозяйственной деятельности определяется целеполаганием ее - воспроизводство населения и сохранение социальной стабильности социума. Ограниченность экономического роста, присущая традиционной экономике согласно воззрениям сторонников «классической школы модернизации», проистекает не из технологической несостоятельности, а оттого, что не ставится цель удовлетворения всех потребностей каждого члена общества. Общество сознательно ограничивает отдельного индивида, выбирая оптимальный для конкретных природных условий способ природопользования. В «традиционном обществе» целью является удовлетворение потребностей, а не потребление благ само по себе. Названный признак традиционного хозяйства - зависимость между окружающей средой и формами хозяйственной деятельности - является системообразующим его фактором, поскольку именно он собирает воедино все хозяйственные приемы, методы использования ресурсов, знания об окружающей среде, а также отвечает формальным условиям системообразующего фактора, ибо: 1) объективно существует, 2) характеризует цель деятельности, 3) является источником системы и поддерживает ее равновесие.

Второй признак, тесно связанный с первым, - натуральный характер хозяйства. Экономика, зависящая напрямую от природных условий, оптимально подходящая к окружающей среде, ставящая целью воспроизводство населения и сохранения существующей социальной системы позволяет иметь все необходимое для жизни, не прибегая к обмену. Обмен может и существовать, но он не выступает главным способом перераспределения благ, и уж тем более - основной формой развития экономических отношений.

Третий признак, также проистекающий из первого и связанный со вторым, - наличие комплекса экологических традиций, в основе которого - рациональный расчет, понимание необходимости разумного использования природных ресурсов, ибо конечная цель любой общности - ее, общности, фризическое сохранение. «Продолжение рода» это не красивые слова, это условие существования популяции, для которой не важен отдельно взятый индивид, важна популяция в целом.

С этим связан четвертый признак - примат общественных экономических интересов относительно индивидуальных экономических интересов. Отсюда и зависимость хозяйственной деятельности от обычаев, традиций, религиозных установок, политических тенденций, «встроенность» экономических отношений в социальные. Общественный контроль может осуществляться путем контроля над перераспределением продуктов потребления, регламентации приемов хозяйственной деятельности, распоряжения средствами производства. Цель всего этого ограничить проявления индивидуализма в экономике, поскольку он противостоит интересам общества в целом. 
Взаимосвязь указанных признаков лежит в основе устойчивости традиционного хозяйства. Стабильность и устойчивость его ошибочно воспринимаются как неспособность к развитию, как склонность к застою. Однако традиционные общества не раз в истории демонстрировали свое умение приспосабливаться к новым условиям (во время массовых миграций, резких изменениях климата и рельефа в окружающей среде, в ходе критических колебаний численности популяций и т.п.). Система традиционного хозяйства демонстрирует способность к прогрессивным изменениям и поразительную гибкость именно потому, что она обусловлена самой природой и развивается, имея целью самосохранение.

Таким образом, представляется возможным определить «традиционное хозяйство» так: это - научная модель, представляющая собой систему хозяйственных практик, обусловленных окружающей средой, структурированных натуральным производством, наличием экологических традиций, приматом общественных интересов над индивидуальными, и имеющих целью постоянное воспроизводство населения и общественных отношений в интересах фризического сохранение социума.

\section{Список использованной литературы и источников}

1. Макконнелл К. Р. Экономикс: принципы, проблемы и политика / К. Р. Макконнелл, С. Л. Брю. - М. : ИНФРА-М, 2003. — XXXVI, 972 с.

2. Побережников В. И. Переход от традиционного к индустриальному обществу: теоретико-методологические проблемы модернизации / В. И. Побережников. - М. : РОССПЭН, 2006. - 240 с.

3. Поланьи К. Экономика как институционально оформленный процесс / К. Поланьи [Электронный ресурс] // Экономическая социология. - 2002. T. 3. — № 2. — С. 62-73. — Режим доступа : https://ecsoc.hse.ru/data/t3_n2.pdf

4. Ростоу В. В. Стадии экономического роста / В. В. Ростоу. - Нью-Йорк : Изд-во Фредерик А. Прегер, 1961. — 239 с.

5. Титов В. Н. Неформальная экономика в России: исторические традиции / В. Н. Титов // Общественные науки и современность. — 2008. — № 5. - С. 100-110.

6. Традиционная экономическая система: ее плюсы и минусы. Так ли она плоха? [Электронный ресурс] // Yalnvestor.guru : Журнал о деньгах и инвестициях [сайт]. - Режим доступа : https://yainvestor.guru/teoriya-finansov/ tradicionnaya-economika

\section{Информация об авторе}

Курышов Андрей Михайлович - кандидат исторических наук, доцент, кафедра истории и международных отношений, Байкальский государственный университет, 664003, г. Иркутск, ул. Ленина, 11; e-mail: akm882@ya.ru

\section{Author}

Andrei M. Kuryshov - PhD in History, Associate Professor, Chair of History and International Relationships, Baikal State University, 11 Lenin St., 664003, Irkutsk, Russia; e-mail: akm882@ya.ru 